\title{
Appreciation Makes Students Grow Healthy and Self-confident
}

\author{
Huaiyuan Fang and Qingfang Cao \\ Feixian Campus, Linyi University, Linyi, Shandong, China \\ huaiyuanfang@126.com
}

\begin{abstract}
Keywords: Appreciation Education; Confidence; Developing Personality; Acknowledging
\end{abstract} Differences

\begin{abstract}
At present, there are many bad social phenomena of d among teenagers, which promotes the research and implementation of appreciation education. This article states the connotation of appreciation education and gives its own understanding about appreciation education.
\end{abstract}

\section{The Connotation of Appreciation Education}

In recent years, there have been many problems among a large number of minors, such as moral disordering, being addicted to the Internet, committing crime, sexual crime, suffering from psychological diseases, running away from home, committing suicide, and so on. The reasons are various. In addition to the family estrangement and lack of parents' raising education, the deeper reason may be that children don't really feel accepted and appreciated. The deepest humanity principle is to be accepted and recognized. As Diesterweg, a German famous educator, said: "The art of education is not to teach knowledge and skills, but to inspire, awake and stimulate". As a kind of incentive mode of education, appreciation education is consistent with the current education and teaching aims. It is a kind of new teaching idea.

Appreciation education is not to praise and encourage, but to appreciate children's behavior results in order to strengthen the child's behavior. It is to appreciate children's behavior process so as to stimulate children's interest and motivation. It is to create the environment to indicate children's direction of developing. It is to alert appropriately, enhance children's psychological experience and correct children's bad behavior. Appreciation education originated from the education phenomenon that parents succeed in teaching their children "earning to speak and learning to walk" in the rate of one hundred percent. It is summary of such mysteries as "recognizing differences, allowing failure and infinite love" in the process of education. It is a kind of brand-new education idea created and fully advocated by Zhou Hong. It is intimately tied up with educator Tao Xing-zhi's education thoughts. Once Mr. Zhou made his deaf daughter Zhou Ting-ting became a doctor studying in the United States using this kind of method. And he cultivated a large number of "Zhou Ting-ting" using the same idea, which was called "Zhou Ting-ting phenomenon" by the news media.

The most important content of appreciation education is to affirm students' learning behavior positively and let students in a positive state in the learning process to make education and teaching effects in an optimal state. Appreciation education is a good idea in family quality education of humanity and culture. Promoting appreciation education is beneficial to protect children's talents, stimulate their potential and return the happiness of growth to children. It is a good idea and method that let the parents and children grow together.

If we appreciate students more, there will be fewer silent despair children. Appreciation education is helpful to the construction of a harmonious class, campus and society. Under the new teaching concept, appreciation education is imperative. Students are rational, so we must enlighten them with reason. And students are emotional, so we should learn to appreciate them.

\section{Appreciation Education Prompts Students to Bloom like Flowers}

Appreciation Education Acknowledges Differences and Allows Failing. The core meaning of "appreciation - success" is that "Appreciation beings success and complaint brings failure". In 
popular words it is the same kind of way as to "teach children how to speak and walk". "Appreciation" embodies the biggest mystery when parents teach children to talk --- acknowledge differences; while "success" embodies another biggest mystery when parents teach children to walk --- allow failing. And differences and failure will not hinder the growth of the students eventually. The deepest humanity principle is hoping appreciation from others. Appreciation is a kind of motivation in essence. It has been proved that a man who gets no appreciation can only play its ability of 20\% - 30\%, but when he receives appreciation, it can reach 3-4 times. All students need to constantly motivate. Appreciation education can help students find confidence, find the potential of self-development and rebuild the spirit home. Students must make some mistakes in the process of growing. Teachers should treat them with a full and developing view, help them find some positive factors, create conditions to carry them forward and let children share the joy of success on the basis of recognition and praise. And children will also be turned into a series of "success" from "being not success". Appreciate them when students fail or lag behind others, and they don't need to spend their school-days in fear and anxiety.

If students can't see their advantages, they will lack of confidence. Appreciation education, on the basis of praise and encouragement, recognizes students and give them confidence. So students can see the advantages when they see their own disadvantages. We should firmly believe that every child has advantages. This is a fundamental evaluation. Educators should be good at finding children's talents, create an encouraging environment and set a realistic goal and requirement for them. The mystery of appreciation education is to arouse children, push the invisible heavy stones making them inferiority away. Then children's potential will erupt like a volcano, unstoppably. All of the learning disabilities are negligible in front of children's enormous potential.

Appreciation education is to let teachers go into the minds of students and get rid of the inappropriate education concepts. It is a harmonious method in which the two generations become friends and grow together, in which teachers enjoy teaching and students are glad to learn, in which teachers highly praise them and students are happy every day.

Join Home and School up to Construct Appreciation Education. First, Teachers and parents are the main implementers in appreciation education. Appreciation enforcers are persons who are recognized in some aspects in individual sub-consciousness, especially those who has certain positive influence. They can be the elderly or peers, acquaintances or strangers. We can say that the range of recognition is the same wide as people's range of activity. But in terms of students, the main implementers are parents and teachers. Teachers not only teach students how to conduct themselves in society but also disseminate love and knowledge and sustain students' emotion world. Appreciation education plays a positive role in students' intelligence development. Children who are lack of recognition are not confident, troubled by the anxiety of "without ownership" all life and there is an invisible shadow in heart. A teacher who knows true love is able to join students together with appreciation spirit of love, kindheartedness, science, and dedication and make them care and love each other. A teacher who aims to develop students for society will give students real recognition, and makes this kind of recognition extend to the family and society, which will make them full of warmth and sunshine. Giving students more tolerance and recognition will not affect the improvement of students' intelligence. On the opposite, it will help to improve students' healthy personality and comprehensive quality.

Influenced by traditional ideas, many parents and teachers misunderstand and don't believe the force of the appreciation education. They only believe that "Spare the rod, spoil the child" and "Talented students are trained by strict teachers." Why many Chinese people going abroad won the Nobel Prize? An important reason is that we limit the development of the child's potential and force children to do everything according to our thinking. Whenever I hear parents say that if their children's results are bad, they would hit them, I will be very sad. I think when the parents will wake, when they can use appreciation education to promote children grow healthily! Some parents believe that "The teacher's one word can be equal to parents' ten sentences. Parents can do little." Honestly speaking, teachers have a great influence on students. But it needs parents' cooperation. Teachers act like doctors and parents act like nurses. Only when they cooperate closely can they 
have good curative effect! Parents are the first teachers of children, and they are the ones who can carry out appreciation education the longest time. Parent's recognition, firm expectations, confidence, and selfless help are the most important cornerstones for children's success. Parents cannot evade the responsibility, and push all the responsibility of education completely to the teachers. They should often communicate and cooperate with teachers and build the most favorable environment for students' healthy and confident growth.

Second, Teachers should implement appreciation education taking classroom teaching as the main channel and discover students' advantages, which can not only bring joy to students, but also enrich their own happiness.

Implementing appreciation education in classroom teaching, teachers can understand and evaluate students fairly. Praising and stimulating students to enhance student's body status, teachers can fully mobilize students' learning, guide students to actively participate in learning, think positively, explore actively, practice consciously, let students always maintain a pleasant emotion participate in the learning process consciously and actively and form a harmonious study atmosphere. Enjoying appreciation education, students can gain knowledge in relaxed and pleasant atmosphere and edify sentiment. Carrying out appreciation education, teachers can grow up slowly together with students, develop students' ability of analysis, creation and practice with patience, love and open heart, cultivate students' confidence and sound personality. So students can develop, show and improve themselves better and faster. And their potential and good moral character can be best played out.

Also, teachers can penetrate appreciation education through the media of homework and examination papers. All the students are very concerned and care about teachers' evaluation to their assignments and papers, because it represents teachers' attitude to his work. The examination is a common way of communication between students and teachers. Checking carefully and evaluating positively reflects not only a teacher's working attitude, but also affects students' attitude to learning. When checking homework, apart from scoring on it, teachers should give some supportive comments, such as "Your homework or paper is very clear, and it is very comfortable to look at it"; "You have made some progress, and continue to work hard." "Today, your performance in class is very outstanding. I'm so happy!" "You conquered yourself once again. I believe that you will do better!" "Are you willing to challenge yourself? I believe you can!" And so on. Seeing your encouraging comments, students will be more confident and devote to learning more consciously. If encountering students with emotional blind after the homework or test, teachers should talk with them, analyze problems and encourage them. After class, teachers should communicate with them again, points out their defects and loopholes and praise their advantages and sparkles. Without recognition, there is no education. Students aspire to get attention and praise from teachers and gain the sense of achievement. When you remember to try appreciation education, you will feel the power of recognition every moment.

Third, Family education is the origin and foundation of the whole education. It is the most basic and also the longest education. Parents are children's first teachers, and family is the cradle of children's growing healthily. Family education is a long-term and systematic project.

Children need a pleasant, relaxed environment to grow up. Appreciation education is to discover the children's strengths, and guide children constantly exert their own advantages, make their own value be reflected, and at the same time get the proper exercise in real life. Parents should look upon children's growth in the view of recognition, trust their children, dig into their potential and advantages. The family should offer children a comfortable environment in which students can showcase their expertise, cultivate their positive optimistic attitude towards life, give children more appreciation and encouragement, help them to find their position, and make grow up healthily in the environment of "I can succeed" so as to improve their comprehensive quality.

Family education must be joint with school education to form a resultant force. Home being synchronous with school to carry out appreciation education can make the education result more effective. In real life, we often find that parents always get together and compare each other's children. If their children are not better than others' in some ways, they will feel guilty because of 
"being not able to teach the child". Practice has proved that creating conditions for parents to participate in education is a catalyst to make children confident and successful. Schools can hold expert lectures, communication meeting, home visits, home-school interaction to help parents to grasp some knowledge of pedagogy and psychology and make them learn some characteristics and laws of modern education so that they can learn to respect, understand and appreciate children and master the art of children education.

Appreciation Education Pays Attention to Developing the Personality. Heart is beautiful, and everything is beautiful. Affection is deep, and everything is deep. Appreciation education is to use our deep affection to shape students' beautiful heart. The disparity between people is not big, like perfume, in which water accounts for about 95 , and only $5 \%$ is different. People are also the same. The difference lies in the key 5\%, including one's characteristics, moral accomplishment, etc. Promoting appreciation education is to make students better show the key 5\%.

As good educators, we should respect the personality development of students'. We should know their personality and specialty, initiative to close to them, and guide the students actively and correctly. For the progress and advantages, we should encourage, appreciate and affirm repeatedly; for the faults and setbacks, we should correct and criticize repeatedly and kindly. During the daily teaching activities, basing on the characteristics of curriculum we should encourage and stimulate students to be "novelty", "unique". At the same time, on the basis of respecting students' individual development, give full play to students' creativity.

Therefore, teachers should respect students' individual development and actively open up a creative path of learning for students. During the process of learning, if students' specialty is not explored, their special ability and developing ability could be stifled. On the other hand, if teachers discover the potential and special skills, their special ability could get developed. So in the future, some students may become poets, musicians, mathematicians, scientists, and so on. So that students' strengths are transformed into real learning ability. So, as good teachers, we should appreciate students' personality, provide guidance, and stimulate students to succeed. As the common saying goes, "High buildings rise from the ground". Appreciation education is the education concept of humanity. It is conducive to protect the children's talents, stimulate interests, develop inner potential, and return the happiness of growing into children.

Appreciation Education Needs "Discovering". Life is not a lack of beauty, but a lack of eyes to find beauty. Also, students are not lack of shining points, but a lack of teachers' eyes to find them. Edison was an extraordinarily clever boy in elementary school, but he was always looked down on. So was Einstein. He often asked some strange questions, and others thought of him as a fool. When Einstein graduated, his father came to the headmaster and asked embarrassedly: "For my child, doing which kind of work can make him prospects?" The headmaster replied: "Whichever kind of job he engaged in, he will be worthless." Fortunately, the two unfortunate children had great mothers who gave them recognition and eager anticipation. Their success and great achievements were inseparable with their mother. Similarly, exploring a successful method of appreciation education can help us teaching and researching. It will also help students to develop themselves better and faster.

Discovery is the precondition of the recognition. There are a lot of students in each class. Only one teacher can't discover all students' potential. Every teacher and parents together should participate and cooperate. So discovery is "love". Discovery is the teachers' diligent and selfless hard work and dedication! We can say that behind appreciation, there is teachers' countless effort. Students need the teacher's praise and recognition in the process of growth. It can bring them a sense of accomplishment to overcome inferiority and fragility. These are inseparable from the appreciation education, teacher's noble personality, selfless efforts and strong sense of responsibility!

\section{Appreciation Education is Imperative.}

Under the new teaching concept, appreciation education is imperative. Appreciation education can make students found his good side from the subconscious, stimulate students' interests and the 
internal potential, make students foster strengths and circumvent weaknesses, overcome psychological inferiority and cowardice, help students to build confidence, stimulate innovation, cultivate the sense of responsibility and improve themselves. Appreciation education is the education of life and love. It is full of emotion and vitality. It pays emphasis on students' advantages and strengths. Under appreciation education, students are trusted, understood, respected and inspired students. Their life condition is stretched, so they can grow in confidence and happiness.

Appreciation education is rains in spring moisten things silently. It is a kind of education "respecting individuality and develop individuality". Based on the demand and characteristic of the development of teenagers, they are in the period of rapid development of self-consciousness. They hope to get others' recognition and acceptance, and are eager to get the respect and recognition of teachers' and other adults'. Appreciation education is in line with the characteristics of the development of students' psychology. It meets the students' inner demand, inspire students' potential, and make students develop themselves better and achieve more.

Recognition prompts success; complaining results in failure. Recognition is not only a kind of understanding, but also a kind of motivation. Appreciation education admits and respects differences. On the basis of that, it finds the best in students and helps them gain self-worth. It makes students positive and gain success. As long as we can truly understand, respect and appreciate them, the nursery of students heart will be sunny and full of the beauty of spring.

\section{References}

[1] L.R.Lu: How can teachers manage classroom. In Urumqi, the Xinjiang youth Publishing House, 2009, 42.

[2] R.S.Tu, S.Q.Tang: The art of communication between teachers and students. Beijing, educational science publishing house, 2007, 205.

[3] F.Y.Ye: Family, school and social education of their respective advantages and integrity. Wisdom, 2011, 22, 26.

[4] Q.H.Miao: Appreciation education of charm. Reading and writing (educational magazine), 2011, 8, 3.

[5] X.Q.Chen: Praise and appreciation in the classroom teaching using reflection. Education Forum, 2010, 12, 41.

[6] H. Zhou: Appreciate your child. Chengdu, Sichuan children's publishing house, 2000, 2.

[7] Z.G.Qiu, Y.C. Zhang: Ideological and political education principle. Beijing higher education Publishing House, 1999, 154.

[8] Institute of Chinese Academy of social sciences dictionary editing room. The modern Chinese dictionary. Business printing museum, 1998, 1105.

[9] Pestalozzi, Z.L. Xia translated: Pestalozzi education works selected. Beijing, the people's education Publishing House, 1992,302.

[10]The Chinese encyclopedia volumes on education. Encyclopedia of China Publishing House, $1985,922$. 